\title{
The management of dermatitis herpetiformis by the gastroenterologist. A series of cases
}

\author{
Lorete Maria da Silva KOTZE' ${ }^{1}$, Luiz Roberto KOTZE ${ }^{1}$, Katia Sheylla Malta PURIM² and \\ Renato NISIHARA ${ }^{1,2}$
}

Received: 15 January 2021 Accepted: 22 June 2021

\begin{abstract}
Background - Dermatitis herpetiformis (DH) is considered a skin celiac disease (CD). The individuals can be seen by primary care professionals or by dermatologists that could refer the patient to a gastroenterologist. Objective - The study aimed to investigate the clinical profile of patients diagnosed with DH and referred to a gastroenterologist and evaluate the treatment response. Methods - We retrospectively studied patients with DH referred to the same gastroenterologist at a private office in Curitiba, Brazil, between January 2010 to December 2019. We included adult patients with a confirmed DH diagnosis. Symptoms, clinical signs, laboratory and histological data, as well as treatment response, were collected. Results - Thirty-three patients were studied ( $60.6 \%$ women, mean age at diagnosis $40.8 \pm 12.61$ years). The median delay for DH diagnosis was four years. Skin involvement was mild in 33.3\%, moderate in $18.2 \%$, and severe in $48.5 \%$. The more frequent gastrointestinal complaints were abdominal distension (78.8\%), flatulence (75.7\%), and gastroesophageal reflux (51.5\%). Depression and anxiety were observed in $81.8 \%$ and anemia in $51.1 \%$. A higher prevalence of bone disorders was associated with higher age at DH diagnosis $(P=0.035)$. Duodenal biopsy showed changes in all patients. Improvement after treatment only with a gluten-free diet (GFD) plus dapsone was verified in $81.2 \%$. Conclusion - Patients with DH referred to a gastroenterologist showed a high frequency of gluten intolerance and systemic complaints. Duodenal histological alterations were found in all the cases. The treatment based on GFD plus dapsone was effective in most patients.
\end{abstract}

Keywords - Dermatitis herpetiformis; treatment; complaints.

\section{INTRODUCTION}

Dermatitis herpetiformis $(\mathrm{DH})$ is an immune-mediated chronic recurrent disorder caused by gluten intolerance $(\mathrm{GI})^{(1)}$ and is considered a skin celiac disease $(\mathrm{CD})^{(2,3)}$. The pathophysiology of $\mathrm{DH}$ is complex and involves genetic factors (HLA predisposition), environment trigger (gluten), and dysregulation of the immune system $^{(4)}$. In most cases, patients with DH are attended by primary care physicians or by dermatologists and then referred to a gastroenterologist to ensure better management of the disease and related complications and control by a gluten-free diet (GFD) that is essential for treatment ${ }^{(5)}$. There are few studies stressing the importance of GI and systemic symptoms in patients with DH and complications consequent to malabsorption of nutrients, as anemia and bone disease. The treatment of choice is a life-long GFD which resolves the rash and enteropathy and offers a good prognosis ${ }^{(6)}$. The relief of symptoms results in humor benefits and better quality of life $\mathrm{e}^{(2)}$.

The study aimed to investigate the broad clinical profile of patients diagnosed with $\mathrm{DH}$ and referred to a gastroenterologist and evaluate treatment response.

\section{METHODS}

Approval was obtained from the Ethics Committee of Mackenzie Evangelical School of Medicine. The procedures used in this study adhere to the tenets of the Declaration of Helsinki, and all participants signed consent.

This retrospective study is a series of cases studied on patients with a confirmed diagnosis of DH by skin biopsies. Noteworthy, all the cases were attended by the same gastroenterologist at a referred private office in Curitiba, Brazil, from January 2010 to December 2019. These patients were referred to this gastroenterologist for clinical approach and management with a GFD. Patients with other concomitant skin diseases and incomplete medical charts were excluded.

All data were collected from the medical charts of the patients. Information on gender, age, period of the onset of the symptoms, degree of skin involvement, gastrointestinal (GI) complaints, humor distress, presence of anemia, bone disease evaluation by dual-energy X-ray absorptiometry (DEXA) was collected at the first consultation with the gastroenterologist. The presence of autoantibodies IgA anti-endomysium was investigated by indirect immunofluorescence or IgA anti-tissue transglutaminase (ELISA) and HLA-DQ2/DQ8.

All patients underwent upper GI endoscopy with two or three biopsies from the bulb and four to five fragments of the second portion of duodenal mucosa while on a gluten-containing $\operatorname{diet}^{(7)}$. The histological findings were reported according to Marsh classification $^{(8)}$. The response to a GFD and the combination of GFD plus drugs were investigated. Treatment of DH was done following several authors' guidelines ${ }^{(2,3,6)}$. Firstly, a strict GFD was recommended to all patients for one month. If there was no improvement of the skin

Declared conflict of interest of all authors: none

Disclosure of funding: no funding received

Universidade Federal do Paraná, Setor de Ciências da Saúde, Curitiba, PR, Brasil. ${ }^{2}$ Universidade Positivo, Departamento de Medicina, Curitiba, PR, Brasil.

Corresponding author: Renato Nisihara. E-mail: renatonisihara@gmail.com 
lesions, dapsone was prescribed, with posology determined by the severity of the clinical manifestation and patient weight. Patients with severe skin symptoms at the time of diagnosis were immediately given GFD and dapsone. The time of use and the dose were adapted according to the drug efficacy response ${ }^{(2,9)}$. Dapsone was discontinued as early as possible if the skin symptoms disappeared. GFD was recommended for all life. Azathioprine was prescribed if GFD plus a high dose of dapsone did not improve the lesions (refractory cases $)^{(10,11)}$. In addition, reports of other immune-mediated diseases (IMDs) previously to the diagnosis of $\mathrm{DH}$ and the family history of these affections were asked to patients.

The data was summarized in frequency and contingency tables. The Fisher test was used to compare nominal data. Unpaired $t$ tests or Mann Whitney tests were used to compare numerical data. Data distribution was evaluated by the Shapiro Wilkin's test. The adopted significance level was 5\%.

\section{RESULTS}

Thirty three patients were studied, being 20/33 (60.6\%) women and $13 / 33(39.4 \%)$ men $(P=0.08)$. All were Caucasians, with a mean age at diagnosis $40.8 \pm 12.61$ years, similar between the genders. The diagnostic delay showed a median age of 4 years $(I Q R=1-12)$, between 0 to 42 years. Age at diagnosis and severity of DH was not associated with delay in diagnosis $(P=0.19$ and $P=0.35$, respectively). Autoantibodies (IgA EmA or IgA tTG) were positive in $59.3 \%$ $(16 / 27)$ patients. HLA DQ2/DQ8 was determined in 13/33 cases, of which $86.7 \%$ were had HLA-DQ2 and $13.3 \%$ DQ8 positive.

At the first consultation, the degree of skin involvement evaluated was considered mild in $33.3 \%$ (11/33), moderate in $18.2 \%$ $(6 / 33)$, and severe in $48.5 \%(16 / 33)$. TABLE 1 shows frequencies of GI symptoms and clinical signs at the first gastroenterological consultation. The more frequent were abdominal distension $(78.8 \%)$, flatulence $(75.7 \%)$, and gastroesophageal reflux $(51.5 \%)$. Anemia was present in $51.1 \%$ of the cases, the iron deficiency being more frequent than vitamin B12 deficiency. Regarding bone disorder, osteopenia was detected in $48 \%$ of the cases and osteoporosis in $8 \%$. A higher prevalence of bone disorders was associated with higher age of $\mathrm{DH}$ at diagnosis $(P=0.035)$. No occurrence of fracture was informed. In addition, a high prevalence of humor disorders $(81.8 \%)$ revealed more depression than anxiety, without significant difference comparing gender, age, or disease severity.

Intestinal biopsy showed changes similar to the histologic findings observed in CD patients in all of the cases. According to Marsh classification $^{(8)}$, Grade I was detected in $24.4 \%$ (8/33), Grade II in $21.1 \%(7 / 33)$, and Grade III in 54.5\% (18/33). FIGURE 1 shows that Marsh III was more frequent in patients with severe forms of $\mathrm{DH}$, however, without significant difference $(P=0.14)$.

Only female patients reported other IMD 10/33 $=(30.3 \%)$ being found hypothyroidism (seven cases), endometriosis (two cases), and type 1 diabetes mellitus (one case). About familial history, $45.4 \%(15 / 33)$ of the patients informed other relatives with a gluten-related disorder, being DH in $24.2 \%(8 / 33)$ and CD in $18.2 \%$ $(6 / 33)$ of the cases.

The treatment preconized before the reference to the gastroenterologist was adjusted. Strict GFD was recommended for all patients, and 11/33 (33.3\%) with mild/moderate disease referred had significant improvement of the skin lesions only with diet. Patients without improvement (22/33) remained on GFD and dapsone, with dose ranges from 25 to $400 \mathrm{mg}$ (average dose of $100 \mathrm{mg}$ per
TABLE 1. Frequencies of gastrointestinal symptoms and clinical signs, detection of anemia, bone disease, and humor disorder in the studied patients with dermatitis herpetiformis $(n=33)$.

\begin{tabular}{lcc}
\hline Symptoms and clinical signs & $\mathbf{n}$ & $\%$ \\
\hline Abdominal distension & 26 & 78.8 \\
Flatulence & 25 & 75.7 \\
Gastroesophageal reflux & 17 & 51.5 \\
Diarrhea & 13 & 39.3 \\
Epigastric pain & 11 & 33.3 \\
Constipation & 10 & 30.3 \\
Mouth ulcers & 10 & 30.3 \\
Mal digestion & 8 & 24.2 \\
Nausea & 8 & 24.2 \\
Weight loss & 6 & 18.2 \\
Vomitus & 3 & 9.1 \\
Anemia $\mathrm{n}=33$ & 17 & 30.3 \\
Iron deficiency & 14 & 42.3 \\
B12 vitamin deficiency & 3 & 9.1 \\
Both & 4 & 12.1 \\
Bone disorder $\mathrm{n}=25$ & 14 & 56.0 \\
Ostheopenia & 12 & 48.0 \\
Ostheoporosis & 2 & 8.0 \\
Humor disorder $\mathrm{n}=33$ & 27 & 81.8 \\
Depression & 17 & 51.5 \\
Anxiety & 10 & 30.3 \\
\hline
\end{tabular}

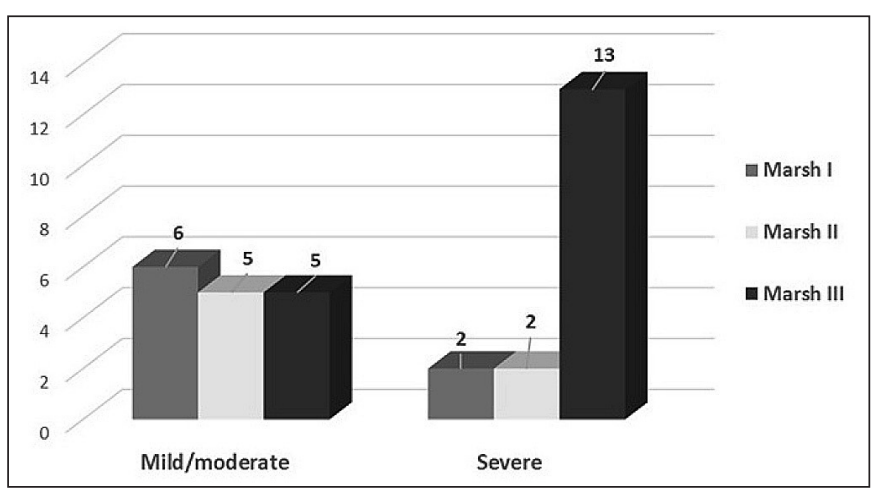

FIGURE 1. Severity of clinical presentation of dermatitir herpetiformis and findings in duodenal biopsy according to Marsh's classification. Marsh I: infiltrative lesion, normal villous architeture and mucosa, IEL increase $(>30-40$ lymphocytes/enterocytes counted). Marsh II: hyperplasctic lesion; similar to Marsh I, but it al also presents crypt hyperplasia. Marsh III: destrutive lesion, subdivided in IIIa - partial villous atrophy; IIIb - subtotal villous atrophy, and IIIc - total villous atrophy.

day) adjusted individually. The drugs were interrupted according to the evolution of each case as soon as possible, and GFD was maintained. Therefore, after 30 days, $81.8 \%$ of patients that used this association had improvement. One patient showed jaundice 2 weeks after starting dapsone, so this drug was excluded, and sulfasalazine was prescribed. Two patients did not improve until intentional denning or accidental ingestion of gluten and a high dose of dapsone, so azathioprine was recommended. For one male patient, this drug caused rapid improvement and, after 12 months, could he stop the medication. Another female patient is using azathioprine until now with an adjusted dose. As expected, the GI complaints disappeared with GFD. Anemia and bone disorders were treated with repositions in cases where they were necessary together with a GFD. Humor distresses were reviewed in the follow-up. 


\section{DISCUSSION}

This study presents data showing a high prevalence of digestive and systemic symptoms CD-like related and changes in duodenal mucosa in Brazilian patients firstly diagnosed with DH who were referred to a gastroenterologist. In addition, they presented a good response to GFD and dapsone.

In our study, a slight preponderance of women was verified, and the mean age was very similar between genders as referred to in the literature. Some studies from Europe ${ }^{(4)}$ and North America ${ }^{(12)}$ report a 2:1 prevalence of DH between male and female patients and the onset of symptoms at 40.1 years for men and 36.2 years for women.

In this study, independently of the severity of $\mathrm{DH}$ or age of the patients, the delay in diagnosis ranged from 1 to 42 years. Only in three cases, the diagnosis was done in less time than one year. Considering the natural history of the DH that shows periods of spontaneous remission and exacerbations, doctors cannot be aware of diagnosing this affection. Physical examination alone may suggest $\mathrm{DH}$ due to the morphology and distribution of the lesions being very characteristic. So, why delay in the diagnosis of $\mathrm{DH}$ in patients with skin lesions? Clinical presentation of $\mathrm{DH}$ is not easy to recognize by general practitioners or other professionals due to the variation in the presentation of skin lesions due to the intense itch and scratching, delaying the diagnosis ${ }^{(13)}$. In addition, the cutaneous symptoms are troublesome and decrease the QoL of the patients ${ }^{(13)}$. Serology could be used for DH screening; however, in this study, $59.3 \%$ of patients had positive serology to IgA EmA or IgA anti-tTG. In Italy, Schiepatti et al. reported positivity in $70-75^{0} 0^{(14)}$ and Antiga et al. $50-95 \%{ }^{(1)}$. Adult patients with DH commonly can exhibit a negative serology, making duodenal biopsy mandatory ${ }^{(16)}$.

Regarding digestive complaints, abdominal distention, flatulence, and gastroesophageal reflux were the most prevalent, as reported in other gluten-related diseases ${ }^{(17)}$. On opposite sides, Holmes et al. referred that $90 \%$ of the patients with DH do not present GI symptoms ${ }^{(18)}$, and Reunalla et al. described symptoms in only $20 \%$ of cases in Finland ${ }^{(3)}$. Rose et al., in Germany, in 32 patients retrospectively studied, reported that none of the patients reported GI symptoms although 29 cases presented CD-like changes at histology ${ }^{(19)}$. Interestingly, oral lesions were described as extremely rare in $\mathrm{DH}^{(20)}$. However, $30.3 \%$ of our patients reported mouth ulcers. These findings could result from gluten action or deficiencies of iron, folic acid, or vitamin $\mathrm{B} 12^{(20)}$. The presence of GI symptoms and signs were found independently of the severity of the skin lesions, regardless of histologic findings.

We found a high frequency of depression $(51.5 \%)$ and anxiety $(30.3 \%)$, higher than those pointed out by Mansikka et al. in Finland $(28.7 \% \text { of anxiety and } 18.8 \% \text { of depression })^{(16)}$. Thus, the skin disease can cause psychological problems to patients, low self-esteem, and interfering with the $\mathrm{QoL}^{(6,7)}$.

Anemia was detected in $51.5 \%$ of the cases due to iron or vita$\min \mathrm{B} 12$ deficiencies, or both, as pointed out by other authors ${ }^{(2,18)}$. In addition, bone disorders were found in $56 \%$ of studied patients, mainly osteopenia. There are scarce reports about bone disorders in patients with DH, and the results are conflicting. Abuzakouk et al. reported no evidence of bone disorders despite evidence of enteropathy ${ }^{(21)}$. On the other hand, Di Stefano et al., alert to significant changes in bone mass, similar to observed in patients with $\mathrm{CD}^{(22)}$. Garcia-Manzanares et al. pointed out the relation between bone disorders and higher grades of villous atrophy, a fact observed in some patients in the present study ${ }^{(23)}$.
Among our cases, all showed enteropathy on duodenal biopsy, and the severity of the intestinal changes did not differ according to the age or gender of the patients. However, in patients with a severe presentation of DH, there was a predominance of Marsh III. There are some controversies about the indication of duodenal biopsy for patients with DH. According to Holmes et al. ${ }^{(18)}$, a small bowel biopsy is required in all patients. Salmi et al. reported that $100 \%$ of the patients with DH have some intestinal disease, varying the extent of the lesions ${ }^{(6)}$. Mansikka et al. related, in 181 patients with $\mathrm{DH}, 72 \%$ of partial or total villous atrophy ${ }^{(16)}$. Schiepatti et al. informed that there is an increased number of intraepithelial lymphocytes in almost $100 \%$, but true villous atrophy in only $70-75 \%$ of patients ${ }^{(14)}$. The authors of the present research suggest biopsy in all the cases of $\mathrm{DH}$ at diagnosis because if in the follow-up some evidence of GI complication or malignancy is suspected, there are elements for comparison.

According to Holmes et al. ${ }^{(18)}$, family studies indicate that $5 \%$ of first-degree relatives also have DH or CD. In this study, 1/3 of first-degree relatives had a diagnosis of DH, DC, or both. These findings reinforce the close monitoring of first-degree relatives of patients with $\mathrm{DH}$.

A strict GFD is the first line of treatment in DH and can improve skin lesions and intestinal injuries. The consultation with a dietitian is recommended for help in the adherence to a GFD. The dermatological condition can respond slowly to a GFD (1/3 of the patients of this study) but undergoes prompt resolution with the addition of oral dapsone. Dapsone relieves the DH rash and itch effectively but does not affect enteropathy ${ }^{(10,11)}$. Other drugs as azathioprine can be used in patients with "refractory DH," like for $\mathrm{CD}$, for a subgroup of patients in whom clinical symptoms and small bowel villous atrophy do not recover ${ }^{(10,11)}$. This study has limitations related to retrospective research. Despite a reasonable sample for the period evaluated, this is a single-center study.

DH is a treatable condition with a favorable prognosis ${ }^{(7)}$. However, independently of the physician responsible for the management, a celiac disease-like protocol for which comprehensive investigation is highly recommended. The present study's findings reinforce the need for an interprofessional team to better manage DH cases, even in asymptomatic enteropathy. The ideal is the involvement of a dermatologist, gastroenterologist, dietician, and psychologist.

In conclusion, patients with $\mathrm{DH}$ referred to a gastroenterologist showed a high frequency of GI and systemic symptoms independently of the severity of the skin lesions. Duodenal mucosa showed histological alterations in all the cases. The treatment based on GFD or dapsone was effective in most patients.

\section{Authors' contribution}

All authors contributed to the study conception and design. Material preparation, data collection were performed by: Kotze LMS, Kotze LR, Purim KSM. The data analysis and the first draft of the manuscript was done by: Kotze LMS and Nisihara R and all authors commented on previous versions of the manuscript. All authors read and approved the final manuscript.

\section{Orcid}

Lorete Maria da Silva Kotze: 0000-0003-2683-6132.

Luiz Roberto Kotze: 0000-0001-8456-4361.

Katia Sheylla Malta Purim: 0000-0001-9982-6408.

Renato Nisihara: 0000-0002-1234-8093. 
Kotze LMS, Kotze LR, Purim KSM, Nisihara R. O manejo de dermatitis herpetiformis pelo gastroenterologista. Uma série de casos. Arq Gastroenterol. 2021;58(4):429-32.

RESUMO - Contexto - A dermatite herpetiforme (DH) é considerada como a doença celíaca (DC) da pele. Os pacientes podem ser atendidos por profissionais do atendimento primário ou por dermatologistas que podem encaminhar o paciente a um gastroenterologista. Objetivo - Os objetivos do estudo foram investigar o perfil clínico dos pacientes com diagnóstico de DH encaminhados a um gastroenterologista e avaliar a resposta ao tratamento. Métodos - Foram investigados retrospectivamente pacientes com DH encaminhados ao mesmo gastroenterologista em consultório particular em Curitiba, Brasil, entre janeiro de 2010 a dezembro de 2019. Foram incluídos pacientes adultos com diagnóstico confirmado de DH. Dados sobre sintomas e sinais clínicos, dados laboratoriais, histológicos e resposta ao tratamento foram coletados. Resultados - Foram estudados 33 pacientes (60,6\% mulheres, média de idade 40,8 $\pm 12,61$ anos). O atraso médio para o diagnóstico de DH foi de 4 anos. O envolvimento cutâneo foi considerado leve em $33,3 \%$, moderado em $18,2 \%$ e grave em $48,5 \%$. As queixas gastrointestinais mais frequentes foram distensão abdominal (78,8\%), flatulência $(75,7 \%)$ e refluxo gastroesofágico (51,5\%). Depressão e ansiedade foram observadas em $81,8 \%$ e anemia em $51,1 \%$. Maior prevalência de alterações ósseas foi associada à maior idade ao diagnóstico de $\mathrm{DH}(P=0,035)$. A biópsia duodenal mostrou alterações em todos os pacientes. A melhora após o tratamento apenas com dieta sem glúten e/ou dapsona foi verificada em $81,2 \%$. Conclusão - Pacientes com DH encaminhados ao gastroenterologista apresentaram alta frequência de queixas gastrointestinais e sistêmicas. Alterações histológicas duodenais foram encontradas em todos os casos. O tratamento à base de dieta sem glúten e/ou dapsona foi eficaz na maioria dos pacientes.

Palavras-chave - Dermatite herpetiforme; queixas; tratamento.

\section{REFERENCES}

1. Ludvigsson JF, Leffler DA, Bai JC, Biagi F, Fasano A, Green PH, et al. Sanders DS, Walker MM, Zingone F, Ciacci C. The Oslo definitions for coeliac disease and related terms. Gut. 2013;62:43-52.

2. Kotze LMS. Dermatitis herpetiformis, the celiac disease of the skin. Arq Gastroenterol. 2013;50:321-5.

3. Reunala T, Salmi TT, Hervonen K, Kaukinen K, Collin P. Dermatitis herpetiformis: A common extraintestinal manifestation of coeliac disease. Nutrients. 2018;10:602-10

4. Bolotin D, Petronic-Rosic V. Dermatitis herpetiformis. Part I. Epidemiology, pathogenesis, and clinical presentation. J Am Acad Dermatol. 2011;64:1017-24

5. Plotnikova N, Miller JL. Dermatitis herpetiformis. Skin Therapy Lett. 2013; 18:1-3.

6. Salmi TT, Hervonen K. Current concepts in dermatitis herpetiformis. Acta Derm Venereol. 2020; 100:adv00056.

7. Rubio-Tapia A, Hill ID, Kelly CP, Calderwood AH, Murray JA. American College of Gastroenterology Clinical Guideline: Diagnosis and Management of Celiac Disease. Am J Gastroenterol. 2013;108:656-77.

8. Marsh MN. Mucosal pathology in gluten sensitivity. In: Marsh MN. Coeliac disease. Oxford, Blackwell Scientific Publications; 1992, pp. 136-91.

9. Vale ECSD, Dimatos OC, Porro AM, Santi CG, Consensus on the treatment of autoimmune bullous dermatoses: dermatitis herpetiformis and linear $\operatorname{IgA}$ bullous dermatosis - Brazilian Society of Dermatology. Ann Bras Dermatol. 2019;94:48-55.

10. Schmidt E. Optimizing therapy in patients with severe autoimmune blistering skin disease. Hautarz. 2009;60: 633-40.

11. Hervonen K, Salmi TT, Ilus T, Paasikivi K, Vornanen M, Laurila K, et al Dermatitis herpetiformis refractory to gluten-free dietary treatment. Acta Derm Venereol. 2016;96:82-6.

12. Zone JJ. Skin manifestations of celiac disease. Gastroenterology. 2005;128 S87-S91.
13. Mansikka E, Salmi T, Kaukinen K, Collin P, Huhtala H, Reunala T, Hervonen K. Diagnostic delay in dermatitis herpetiformis in a high-prevalence area. Acta Derm Venereol. 2018;98:195-9.

14. Schiepatti A, Savioli J, Vernero M, de Andreis FB, Perfetti L, Meriggi A, Biagi F. Pitfalls in the diagnosis of coeliac disease and gluten-related disorders. Nutrients. 2020;12:1711-20.

15. Antiga E, Maglie R, Quintarelli L, Verdelli A, Bonciani D, Bonciolini V, Caproni M. Dermatitis herpetiformis: Novel perspectives. Front Immunol. 2019;10:1290. eCollection 2019.

16. Mansikka E, Hervonen K, Kaukinen K, Collin P, Huhtala H, Reunala T, Salmi T. Prognosis of dermatitis herpetiformis patients with and without villous atrophy at diagnosis. Nutrients. 2018;10:641.

17. Lima RF, Kotze LM, Kotze R, Chrisostomo KR, Nisihara R. Gender-related differences in celiac patients at diagnosis. Arch Med Res. 2019;50:437-41.

18. Holmes G, Catassi C, Fasano A. Fast Facts: Celiac Disease. 2009. Dermatitis herpetiformis. P 83-90.

19. Rose C, Bröcker EB, Zillikens D. Clinical, histological and immunopathological findings in 32 patients with dermatitis herpetiformis Duhring. J German Society Dermatol. 2010;8:265-71.

20. Rodrigo L, Beteta-Gorriti V, Alvarez N, Gómez de Castro C, de Dios A, Palacios L, Santos-Juanes J. Cutaneous and mucosal manifestations associated with celiac disease. Nutrients. 2018;10:800.

21. Abuzakouk M, Barnes L, O'GormAN n, o'Grady A, Mohamed B, McKenna MJ, et al. Dermatitis herpetiformis: No evidence of bone disease despite evidence of enteropathy. Dig Dis Sci. 2007;52:659-64.

22. Di Stefano M, Jorizzo RA, Veneto G, Cechetti L, Gasbarrini G, Corazza GR. Bone mass and metabolism in dermatitis herpetiformis. Dig Dis Sci. 1999;44:2139-43.

23. Garcia-Manzanares A, Tenias JM, Lucendo AJ. Bone mineral density correlates with duodenal Marsh stage in newly diagnosed adult celiac patients. Scand J Gastroenterol. 2012;47:927-36. 